NBER WORKING PAPER SERIES

\title{
THE INCIDENTAL FERTILITY EFFECTS OF SCHOOL CONDOM DISTRIBUTION PROGRAMS
}

\author{
Kasey S. Buckles \\ Daniel M. Hungerman \\ Working Paper 22322 \\ http://www.nber.org/papers/w22322 \\ NATIONAL BUREAU OF ECONOMIC RESEARCH \\ 1050 Massachusetts Avenue \\ Cambridge, MA 02138 \\ June 2016
}

We thank Guillermo Roque, Connor Voglewede, and Madeleine Organ for excellent research assistance, and participants at the 2015 ASSA conference, the 2015 SOLE/EALE conference, the 2015 Family Economics Workshop at the University of Montreal-CIREQ, the 2016 Economics of the Family Conference at the Notre Dame London Global Gateway, and the 2015 NBER Children's and Education programs for their comments. During this paper's composition, Professor Hungerman received funding from the John Templeton Foundation for an unrelated project. Email the authors at kbuckles@nd.edu and dhungerm@nd.edu. The views expressed herein are those of the authors and do not necessarily reflect the views of the National Bureau of Economic Research.

NBER working papers are circulated for discussion and comment purposes. They have not been peer-reviewed or been subject to the review by the NBER Board of Directors that accompanies official NBER publications.

(C) 2016 by Kasey S. Buckles and Daniel M. Hungerman. All rights reserved. Short sections of text, not to exceed two paragraphs, may be quoted without explicit permission provided that full credit, including $\odot$ notice, is given to the source. 
The Incidental Fertility Effects of School Condom Distribution Programs

Kasey S. Buckles and Daniel M. Hungerman

NBER Working Paper No. 22322

June 2016

JEL No. J13

\section{ABSTRACT}

While the fertility effects of improving teenagers' access to contraception are theoretically ambiguous, most empirical work has shown that access decreases teen fertility. In this paper, we consider the fertility effects of access to condoms - a method of contraception not considered in prior work. We exploit variation across counties and across time in teenagers' exposure to condom distribution programs in schools. We find that access to condoms in schools increases teen fertility by about 10 percent. These effects are driven by communities where condoms are provided without mandated counseling.

Kasey S. Buckles

University of Notre Dame

Department of Economics

436 Flanner Hall

South Bend, IN 46556

and NBER

kbuckles@nd.edu

Daniel M. Hungerman

Department of Economics

University of Notre Dame

439 Flanner Hall

Notre Dame, IN 46556-5602

and NBER

dhungerm@nd.edu 


\section{Introduction}

The US teen birth rate is far above that of other industrialized countries, and one controversial approach to addressing the issue has been to improve young people's access to contraception. Proponents of this approach argue that improved access will reduce the likelihood of an unwanted pregnancy among sexually active teenagers (e.g., Boonstra, 2014). However, others have argued that providing improved access to contraception to teenagers condones or facilitiates sexual activity and could even increase teen births (Paton, 2002).

The effect of contraceptive access on teen fertility is therefore an empirical question, and a large body of work in the social sciences has considered it. Much of this work has focused on access to oral contraception (the Pill) in the 1960s and 1970s, finding that access not only lowered teen fertility, but also improved long-term economic and family outcomes (Goldin and Katz, 2002; Bailey, 2006; Pantano, 2007; Guldi, 2008; Ananat and Hungerman, 2012). Recent work has also examined the effects of access to long-acting reversible contraceptives (LARCs) and to emergency contraception. Access to LARCs decreases teen childbearing (Lindo and Packham, 2015), while access to emergency contraception increases sexually-transmitted infections—-suggesting a behavioral response_-but has no effect on teen fertility (Girma and Paton, 2011; Durrance, 2013).

In this paper, we consider the effects of condom access on teen fertility-a contraceptive method that has received much less attention in the literature. Despite the fact that research on other methods consistently suggests that contraceptive access lowers teen fertility (or in some cases has no effects), there are reasons to believe that the effects of condom access programs may be different. First, condoms are a relatively less effective method of birth control—one-year failure rates for condoms are more than double those of the Pill (Trussell, 2011). Second, condom use relies more heavily on the male partner, whereas the methods mentioned above rely more heavily on the female. This may be important given gender differences in the costs of an unintended pregnancy. Third, condoms are used at the time of intercourse, as opposed to LARCs or the Pill which can be taken in advance. Fourth, the Pill and LARCS are effective over a longer term, making the decision to use them a long-term decision rather than a short-term one.

A careful study of the effects of condom distribution has important implications for policy, as both the American Academy of Pediatrics in the United States and the National Institute for Health and Care Excellence in the UK have recently advocated for condom distribution in schools 
(American Academy of Pediatrics, 2013; National Institute for Health and Care Excellence, 2014). ${ }^{1}$ School districts in Boston, Buffalo, Chicago, and elsewhere have consequently reconsidered the role of condoms in their schools (Bidgood, 2013; Chicago Tribune, 2014; Tan, 2014).

To our knowledge there is no research that provides rigorous evidence on how condom access in schools_ or condom access more generally_impacts teen fertility. The goal of this paper is to provide such evidence. To do so, we consider a massive policy intervention that affected millions of teenagers during the early 1990s: the introduction of condoms in schools to prevent HIV transmission. During this period, hundreds of schools across the country provided condoms to their students. We construct a national dataset documenting the introduction of condom access programs across the country. We then match these data to national data on birth rates for counties with a population of at least 100,000, allowing us to observe birth outcomes for women of different ages in different communities. By using data and policy variation at the national level, we are able to identify fertility effects that would be missed by using a single school or even a single large school district.

We find clear evidence that access to condoms in schools leads to an increase in teen fertility. This increase is observed in both rigorous regression specifications and in a basic visual inspection of the data. It does not appear to be driven by differential trends or reverse causation and it is robust to using births to slightly older women as a control. The effects are reasonably large in magnitude: access to condoms for the entire high-school-aged population in a county would lead to about 5 extra births per 1,000 teenage women, or a 10 percent increase relative to the mean. Since the average program covered about one-third of the teenage women in the county, the typical program led to an additional 2 births per 1,000 teenage women.

There are several mechanisms that could drive our results. School condom distribution programs could encourage risky sexual behaviors, promote the use of the condom over methods that better prevent pregnancy, or cause schools to shift resources away from more effective programs. We explore these mechanisms by testing the sensitivity of the results to contextual factors. We find that the fertility increase is driven by communities where condom access was provided without mandated counseling, and that these fertility effects may have been attenuated, or perhaps even reversed, when counseling was mandated

\footnotetext{
${ }^{1}$ In November of 2013, the AAP released a policy statement arguing that "schools should be considered appropriate sites for the availability of condoms" and in March of 2014 a NIHCE statement advocated that free condoms should be "readily accessible" at "schools, colleges, and youth clubs."
} 
as part of condom provision. We also briefly consider the prevalence of sexually transmitted infections (STIs) and find that gonorrhea rates for women rose following condom provision. These estimates are limited by the available data but again are driven by communities providing condoms without counseling. In section 5, we discuss the extent to which these results support the various potential mechanisms.

Our results suggest that the findings of past work on the impacts of access to the Pill and LARCs may not necessarily match the impacts of other contraceptive methods, and that the circumstances of contraception access may matter a great deal. These results also suggest caution both in assessing recent policy proposals for condom provision in schools and in inferring fertility outcomes from small-scale prior studies discussing condom access and sexual behavior. Our findings on the importance of counseling may also help reconcile our results with those of Lovenheim, Reback, and Wedenoja (2014), who show that school-based health clinics offering contraceptive services significantly lowered teen fertility. If health clinics can effectively combine contraception access and counseling, this may lead to very different effects than access alone-a conclusion similar to the one drawn by Kirby (2002).

\section{School Condom Distribution Programs}

\section{A. Overview of Condom Programs}

In the early 1990s, hundreds of schools across the United States began to make condoms available on-site to students. ${ }^{2}$ Discussions of the introduction of these programs at the time overwhelmingly point to concerns with AIDS/HIV as the primary driver (e.g., Banks, 1991; Goldstein and Bates, 1993; Tillman 1992). Adams County School District 14 in Commerce City, Colorado was the first district to implement a school-based condom program directly on school grounds in 1989. The largest district in the country, New York City Public Schools, did so in 1991. The activity in New York began after the appointment of Joseph Fernandez as chancellor following the unexpected death of chancellor Richard Green, who died of an asthma attack after only 14 months on the job; during Green's brief tenure little work was done to address concerns about AIDS (Johnson, 1998). The second-largest district, Los Angeles Unified School District, followed with a condom program in 1992. By the middle of the decade, dozens of school districts had

\footnotetext{
${ }^{2}$ In this section we draw on a wide variety of sources, but particularly noteworthy and extensive discussions can be found Samuels and Smith (1993), Kirby and Brown (1996), and Johnson (1998).
} 
implemented a policy that allowed students to obtain condoms at school.

Typically, condoms were provided by an intermediary, and most schools made condoms available through multiple sources. ${ }^{3}$ The most common method of providing condoms was through a school nurse (including either nurses employed by the district or nurses in clinics employed by outside agencies) and teachers. Nearly half of condom programs also made condoms available from counselors, and about a quarter of programs made condoms available through other employees or the school principal. A small number of schools (less than 5\%) made condoms available from sources such as vending machines or baskets. Most schools made condoms free to obtain, although some suggested or charged a small fee such as 25 cents (Brown et al., 1997). The vast majority of programs were provided in high schools; most programs (about 75\%) were located in what Kirby and Brown call "regular academic schools," but a relatively high proportion were found in alternative schools such as schools for students with children or facing incarceration. About a quarter of all programs were run in conjunction with a school health center that typically provided other services, such as physicals. ${ }^{4}$

Most programs allowed parents to "opt out" on behalf of their children if they wished (although research, e.g., Kirby and Brown (1996) suggests that very few parents-typically just 2 or 3 percent-did so). Most programs were implemented at the district level, and the great majority of programs were adopted by school boards (Leitman, Kramer, and Taylor, 1993).

Several sources agree that a key feature distinguishing programs is whether students were required to receive counseling when requesting a condom. Lewin (1991) writes "even those who argue most vociferously that teen-agers need better access to contraception concede that condom programs may not have much effect unless they include counseling and social support;" MartinezDonate (2004) and Taylor (1991) make similar arguments. As described by Kirby and Brown (1996), "during counseling, students are commonly informed that abstinence is the safest method of protection against STIs; they are also instructed about the proper methods of storing and using condoms." Counseling also emphasized the effectiveness of condoms in preventing STIs. Fortunately, when collecting information about programs we were able to identify in most cases

\footnotetext{
${ }^{3}$ Most of the numbers for this discussion are taken from a national survey of programs conducted by Kirby and Brown (1996).

4 There were far fewer clinics in the early 1990s than today (Lovenheim, Reback, and Wedenoja, 2014), and clinics played a more limited role in providing on-campus access to condoms. For example, according to Johnson (1998, page 89), only two school clinics provided contraception access in NYC in 1987; the number in LA Unified in 1991 was three (Banks, 1991) and in San Francisco that year it was zero (Asmiov, 1992a).
} 
whether or not counseling was mandated by the district; about two-thirds of the programs we use in our study are programs with district-mandated counseling accompanying diffusion.

Previous empirical work on the effects of school condom distribution programs has focused on take-up, condom use, and sexual activity. First, regarding take-up, Kirby and Brown (1996) find that the median school distributed about one condom per student per year, a reasonably large number, although there was large variation with about a fourth of schools distributing less than half a condom per student/year and nearly a sixth of schools distributing more than six condoms per student/year. Alternative schools and smaller schools had higher numbers of condoms distributed.

Of course, taking condoms and using them are separate issues. As noted in Kirby $(2001)^{5}$, and Kirby et al. (1999), condoms may have been already reasonably available to adolescents during this time period, so condom distribution at school might merely crowd out condoms obtained from other locations. Cohen (1999) reviews several studies on the effects of school condom programs on condom use; many studies find that the programs led to greater condom use among sexually active students. Kirby and Coyle (1997) present similar survey results. However, several studies produce inconclusive results; for example Furstenberg et al. (1997) find an insignificant increase in condom use and Schuster et al. (1998) found no significant change in condom use from females. Kirby et al. (1999) compare condom use throughout the Seattle school district to a nationally-representative sample of students in other (non-condom) schools before and after Seattle's diffusion; they strikingly find a statistically significant and economically large decrease in condom use following diffusion. They hypothesize that this decrease might be driven in part by the fact that condoms in Seattle were provided in vending machines and baskets (i.e., without mandatory counseling), so that staff in health centers might have responded to this form of condom access by shifting focus to other behaviors, causing unexpected changes in adolescent contraceptive use.

Opponents of school condom distribution programs argue that the programs condone sexual activity and may therefore increase it. The majority of the empirical evidence on this question finds that condom programs did not increase teen sexual activity; examples include Martinez-Donate et al. (2004), Blake et al. (2003), and even the above Kirby et al. (1999). Wretzel et al. (2011) show that a condom availability program lowered STI rates in one school district.

However, nearly all of this work exploring the effects of condom distribution in schools has suffered from a number of methodological challenges. A well-cited survey by Kirby (2002) notes

\footnotetext{
${ }^{5}$ See the summary discussion of condom access programs in chapter 4, page 115.
} 
that almost no prior study (1) utilizes both pre- and post-access data, (2) compares students gaining access to other students, and (3) employs large sample sizes. One noted exception, Kirby et al. (1999), uses data from 10 high schools, a sample that may be too small to study teen fertility. Subsequent work (e.g., Martinez-Donate et al., 2004; Blake et al., 2003) has also faced these challenges.

In this paper, we provide the first investigation on the effects of school condom distribution on fertility using a rigorous identification strategy and data on condom access programs and teen births from across the country. We describe these data next.

\section{B. Data on Condom Programs}

Using Samuels and Smith (1993), Kirby and Brown (1996), and Johnson (1998) as starting points, and supplementing these sources with popular-press coverage, we collected information on condom distribution programs implemented in the 1980s and early 1990s. This gave us a list of districts with programs making condoms available to schools. We included any district where (a) we had documentation of a district condom access program (b) there was information about whether counseling was required by the district (c) there was information about whether the program was district wide, and, if it was not district wide, which schools participated, and (d) there was clear information available about when the program began. Several districts which had condom programs were dropped from our analysis because they lacked some of this information. ${ }^{6}$

Table 1 lists the districts we identify as districts implementing a condom access program during our period of study. The list includes 22 districts in 12 states (including DC) with a total of 484 affected schools (we discuss this number of schools momentarily). The list shows that most programs were implemented in 1992 or 1993. About two-thirds of the programs feature mandatory counseling. Appendix Table 1 shows how the programs varied along other dimensions, including

\footnotetext{
${ }^{6}$ Many of the programs we lost were in the state of Massachusetts. In the fall of 1991, the Massachusetts Department of Education suggested that schools consider making condoms available to students. Many of the schools and districts in the state did (Nealon, 1993), but in several instances we were unable to locate clear information on the details of a particular program. Programs where the exact timing of implementation was unclear included the programs in Chelsea (MA), Dade County (FL), Hatfield (MA), and Jackson Public School District (MS). Places where we had clear information about the timing of a program but lacked other information included Martha's Vineyard (MA), Palm Beach (FL), Portsmouth (MA), and Somerville (MA). Places dropped because it was unclear which schools or clinics participated include Dallas (TX), Little Rock (AR), and Chicago Public Schools (IL). The Gadsden County School District (FL) could not be matched to the birth certificate dataset as the county's population was too small for inclusion in the data. These districts were excluded from the analysis, although fortunately this still leaves us with the vast majority of students and counties in the country.
} 
the presence of an opt-in/out policy and whether students were charged for condoms.

Given that we compiled our list well after these programs were introduced, there might be a concern that we have missed a large number of programs. Fortunately, this does not appear to be the case. In 1995-just after the explosion of condom access programs-Kirby and Brown undertook a national survey of school condom-access programs. They identified a total of 421 schools with programs, a number quite comparable to the number we identify. ${ }^{7}$ Our count of the number of districts that required counseling also matches the numbers in their survey (see Table 2 in their paper). This gives us confidence that our efforts to collect information have been acceptably thorough. To the extent that we miss programs and thus misclassify a treatment county as a control county, our estimates will be biased towards zero.

While Table 1 shows that condom access programs were in both large school districts and small school districts all over the country, the table also shows that programs were primarily located in the northeast and the west. Table 2 shows that the districts introducing condom programs differed in other ways as well—-they had slightly higher teen birth rates in 1990 than other districts, were more populous, had a lower fraction white, and higher per-capita income. The adopting districts may also have differed in other harder-to-observe ways. One might thus ask why some districts adopted condom access.

As we have mentioned, these programs were an effort to reduce the spread of AIDS and other sexually transmitted infections. But, of course, communities with especially strong concerns about AIDS might have different populations of students than other districts, as Table 2 confirms. We have several responses to this observation. First, the nature of our identification strategy involves comparing changes over time in fertility between condom-adopting communities and other communities so that persistent differences across communities should not confound the analysis. Next, it is possible that divergent trends in outcomes between communities could lead to changes in fertility between communities even absent the adoption of condom programs. For example, it could be that changes in teen birth rates lead to condom programs being introduced, rather than the other way around. Fortunately, all of the national results below include controls for such trends and our findings are robust (as we show) to either parsimonious or more aggressive trend controls; and we present both simple and more sophisticated evidence indicating that reverse causality is not driving

\footnotetext{
${ }^{7}$ We would like to have used their original data for our study. We contacted these authors, and we appreciated their cooperation with us, but unfortunately (albeit understandably) it appears that the original data they collected cannot be located.
} 
the results.

One might wonder whether communities fighting AIDS through condom programs might also choose to fight AIDS in a variety of other ways. Examples could include sexuality and HIV education programs and curricula such as Project IMPACT in NYC (Liebermann, Gray, Wier, Fiorentino, and Maloney, 2000) or the Reducing the Risk program or the SNAPP programs used in California (Kirby, Barth, Leland and Fetro, 1991; Kirby, Korpi, Adivi, Weissman, 1997); holistic after-school programs such as the Children's Aid Society-Carrera after-school program (Philliber, Kaye, Herrling, and West, 2002); and community initiatives outside of schools such as the RESPECT project in Philadelphia (Huges, Furstenberg, and Teitler, 1995) or the service-based Teen Outreach Program used in various cities (Allen, Philliber, Herrling, Kuperminc, 1997). Kirby (2001) provides a survey of these and other programs devoted to adolescent sexuality in the 1980s and 1990s. While these programs used various strategies and presented differing content to adolescents, he finds that the vast amount of evidence suggests that these programs typically lowered or had no effect on most measures of adolescent sexuality. Several studies specifically consider teen pregnancy as an outcome, and here again most available evidence suggests that these either lowered teen pregnancy or had no effect. ${ }^{8}$

Such coincidental efforts would thus be expected to work against our conclusion that school condom distribution programs increased birth rates. Indeed, of the anti-HIV procedures considered by schools in the early 1990s, condoms were uniquely singled out for their potential to unintentionally raise fertility rates (Rafferty and Radosh, 2000; Blake et al., 2003). However, we investigate this concern in two ways. First, we test for changes in the birth rate just before a community adopts condom access in schools. Clear drops in teen pregnancy in treatment communities observed a year or two before condom access would be a signal that these communities may be aggressively fighting AIDS in a variety of ways - for example, with staterecommended or required AIDS education programs. This is a plausible scenario (which, again would likely work against our finding below) as at least some anti-AIDS programs could have predated the early-1990s rise of condom use (Kirby and Coyle, 1997). But consistent evidence that the changes in fertility — and especially increases in fertility — coincide with the years of condom

8 The majority of these programs promoted abstinence as the best method for avoiding STIs and unplanned pregnancies. One possibility is that it was the "mixed-message" of both introducing condoms while focusing education efforts on abstinence that led to the increase in teen pregnancy that we find. Given that sex education in the United States is still primarily abstinence-based, our results could still be relevant today if this were the case. 
diffusion would be difficult to reconcile with this story.

Additionally, in some specifications we control for the birth rate among women age 20-24. These women would have been subject to many of the same public health efforts to address the AIDS epidemic, but should not have been as affected by condom distribution in schools. This strategy also helps us address concerns that the intensity of the crack epidemic may have been correlated with condom access programs, as women 20-24 would also have been exposed to the arrival of crack. We would have liked to have included controls for crack in our main specifications, but were not able to find annual measures at the county level for our sample. We have replicated our results for a subset of cities for which we have information on the arrival of crack from Evans, Garthwaite, and Moore (2012), and our results are robust to the inclusion of these controls.

\section{Estimation}

In order to identify the effect of school condom access programs on teen fertility, we employ a framework that exploits within- and across-county variation in teens' exposure to these programs. While the condom-program information is available at the school or district level, the national birth outcome data we will use in our analysis is available at the county level. As we describe in more detail below, our measure of treatment will be the fraction of high-school-aged women in each county attending a school with a condom program. ${ }^{9}$

We estimate equations of the form:

$$
\mathrm{lbr}_{c t}=\delta \text { Condom }_{c t}+\beta X_{c t}+\theta_{c}+\theta_{t}+T_{c}+\varepsilon_{c t}
$$

where $l b r_{\mathrm{ct}}$ is the log of the live birth rate for women age 15 to 19 in county c and year of conception $\mathrm{t}$ (discussed in more detail below). The variable Condom ${ }_{\mathrm{ct}}$ measures the fraction of high-school-age teens in the county who were in schools with a condom access program; this will exploit variation in the relative magnitude of diffusion across affected counties as compared to simply using a dummy variable for whether any student in a county gains condom access. The numerator is the size of the student population in schools with a program, taken from the 1990 Common Core of Education. We use the 1990 population to avoid concerns about student migration into or out of a public

\footnotetext{
${ }^{9}$ There were 22 affected districts in 21 counties. New York City Public School District covers five counties, while eight Massachusetts districts are housed within five counties and three school districts are housed within Los Angeles County. Our data include a school's district and county, and so we can identify schools in districts with condoms and also the county where these schools are located. Thus our measure of diffusion can accommodate both several districts within a county and districts spanning multiple counties.
} 
school district in response to a program's introduction. ${ }^{10}$ The denominator is the county population of 15-18 year olds in 1990, taken from the 1990 Census. For counties with a condom program, this variable has a mean of 0.37 and a standard deviation of 0.29 . The matrix $X_{\mathrm{ct}}$ includes controls for per-capita county income, per-capita Medicaid payments, and per-capita state unemployment insurance compensation (all from the BEA), total county population in levels and logs, the fraction of the county population that is Hispanic, the fraction white, the fraction black, the fraction under 18, the fraction poor and under 18, and the fraction over age 65 (from decennial censuses and linearly interpolated across years). The terms $\theta_{\mathrm{c}}$ and $\theta_{\mathrm{t}}$ represent county and year dummies, respectively, and $T_{\mathrm{c}}$ represents a set of county-specific time trends.

Annual county-level birth rates are constructed from the National Center for Health Statistics' Natality Detail Files, from 1982 to $2000 .{ }^{11}$ The data provide records for all births in the 50 U.S. states and the District of Columbia, with the exception of a few states that report $50 \%$ of births prior to $1985 .{ }^{12}$ Each record contains detailed information on the mother, father, and baby. Data used in this study include the mother's age and county of residence. County of residence is available for counties with populations greater than 100,000; thus, our group of control counties will be counties with populations greater than 100,000 that did not see condom diffusion). Only one district condom program, in Gadsden county (FL), was dropped because it could not be matched to our birth data. Our estimates include 396 counties in total.

We use these data to construct the numerator for the birth rates, which is the number of births to women ages 15 to 19 that were conceived in a given county and year. ${ }^{13}$ Month of conception is estimated using birth certificate data on month of birth and gestation. The denominator for the birth rate is the population of women ages 15 to 19 in each county, taken from

\footnotetext{
${ }^{10}$ Seattle is a noteworthy district where several schools began distributing condoms in 1993 and more followed in 1995. In this case we adjust the number of students affected over time. Thus, in the year 1995 we increase the estimated fraction of students in Seattle given condom access using the enrollment information from 1990. There are two other counties (Middlesex, MA; and Worcester, MA), where we make similar adjustments as the number of districts in the county with condom access changed over time.

11 We choose this time frame to allow for the identification of pre- and post-trends; in results not shown here we have reproduced Table 3 for alternative sample periods. When later years of the sample are dropped (1997-2000), the results unsurprisingly become more sensitive to the choice of functional form for the county-specific time trends-while we still observe positive effects on fertility, the results are only statistically significant when quadratic trends are used. When we also drop earlier years (1982-1986), only the linear specification is statistically significant.

12 For $50 \%$ sampling states, each observation is doubled.

${ }^{13}$ We use the 15 to 19 range because our interest is in how condom programs affect teen births, and also because women in this range (or their partners) would likely have been affected by school-based programs. Below, we reproduce our results using one-year age intervals.
} 
the 1990 census population count data. ${ }^{14}$ The mean birth rate to women 15 to 19 in our sample, using this method of constructing birth rates, is 54 births per 1000 women. We also construct (a) the birth rate to women 20 to 24 years old and (b) age-specific birth rates for young women for use in alternative specifications. The dependent variable for our regressions is the log of the birth rate. ${ }^{15}$

The key coefficient in equation (1) is $\delta$, which could be interpreted as showing the proportional change in the birth rate from a county going from no students having condom access in schools to all students having condom access in schools. Some specifications will alter (1) to include births to women ages 20 to 24 .

\section{Results}

Before presenting estimates of equation (1), we first consider a simplified investigation of our data. For each of our "treatment" counties implementing a school condom program, we construct a birth ratio equal to the births for women ages 15-19 conceived in year t over births to women ages 20-24 conceived in $\mathrm{t}$. Figure 1 shows the average value of this ratio across counties beginning 5 years before condom access occurs in a county through 5 years after access occurs (year zero is thus the year a program was implemented). The figure shows a prominent and persistent break from trend exactly at the time a condom access program is introduced. Going from one period before a condom program to one period after, the figure indicates a county will on average see about 5 additional children born to teenagers for every 100 children born to women ages 20 to 24 , about a 10 percent increase. The figure shows no evidence of a pre-existing change in relative fertility between these two groups in the years immediately preceding diffusion.

While simple and striking, Figure 1 fails to account for changes in teen births in other communities and does not include any controls. Table 3 presents regression estimates of equation (1) that address these issues. All regressions are weighted by the number of women ages 15 to 19 in a county in 1990. Standard errors are clustered by county. The year a program is introduced is dropped from the regression. The table shows estimates of $\delta$, the coefficient for the variable measuring the fraction of high-school aged teens in a county exposed to a district condom access

\footnotetext{
${ }^{14}$ Redoing our estimates using annual SEER population counts produces qualitatively similar results.

15 Our focus is on live births given the important (and earlier-mentioned) policy concerns related to teen childbearing. But one might wonder if condom access could impact other outcomes, such as abortion. We know of no reliable data on the universe of abortions to women by age group and county across years. However, if diffusion caused unwanted pregnancies and this led to a rise not only in the birth rate (as we find) but also in abortions, then the results below would represent underestimates of the effect of diffusion on unwanted pregnancies.
} 
program. Note that the source of identification that distinguishes treatment group and control group differs between the regression results and the figure. The figure compares adolescent women to slightly older women within the treatment counties, before and after diffusion. The regressions will compare adolescent women in treatment counties to adolescent women in control counties.

However, the results of the regressions are similar to those in the figure. The baseline result in column 1 indicates that in-school-condom access increases teen births; the coefficient suggests that if a county went from no access to access for the entire high-school-age population, the birth rate among women 15 to 19 would increase by about 12 percent (we discuss the magnitude of this effect more below). The next two columns present results using quadratic (column 2) and cubic (column 3) county-specific trends, rather than linear. The estimates are robust to these alternatives and the results do not appear to be driven by pre-existing, or differential, trends. Column 4 presents another investigation of this possibility by including a variable measuring diffusion two years in the future. If the inclusion of this variable dramatically weakened the "true" diffusion variable, this would indicate that communities adopted condom programs following changes in birth rates (rather than the other way around). But the main result is comparable to before; the future-diffusion coefficient is small and insignificant, and the regression along with Figure 1 indicates that preceding increases in birth rates are not driving the estimates.

The last column revisits Figure 1 by including logged births to women 20-24 as a control on the right hand side; the specification is thus a generalization of a regression using, in the spirit of Figure 1, a ratio of birth rates for women 15-19 over women 20-24 (where here the specification allows the coefficient on births to women 20 to 24 to vary, rather than forcing it to be unity). But despite this generalization, and the different nature of identification here, the implied effect of 0.100 is close to before. The results of Table 3 thus indicate that condom access programs increase teen births, and that these estimates are not driven by pre-existing trends. ${ }^{16}$ The coefficients imply that full diffusion would lead to 10 to 12 percent more births to women ages 15 to 19 , or about 5 or 6 additional births per 1000 women off a mean birth rate of 54 per 1000 . Since the average program covered about one-third of the teenage women in the county, the typical program led to an

\footnotetext{
${ }^{16}$ We also explore estimates using birth rates in levels, rather than logs. Using levels typically gives qualitatively similar results to those shown here. The baseline estimate in Table 2 in levels yields a coefficient of 0.55 [se $=0.30$ ], implying a proportional effect of about 10 percent, which is comparable to the effects in Table 2.
} 
additional 2 births per 1,000 teenage women. ${ }^{17}$

Table 4 presents results where births for older women are now modeled not as a control but rather as a dependent variable. Each coefficient in columns 2 and 3 comes from a separate regression. In each regression, the dependent variable is the logged birth rate for women of a particular age or age group. The first row repeats the results from Table 3; the second row shows results for women ages 20 to 24 . The results indicate that condom access leads to significant increases in the teen birth rate but is unrelated to changes in the birth rate for slightly older women.

Our data also allow us to consider births for individual years of age. The rest of Table 4 present results by individual age at birth for ages 15 to 21 . As before diffusion measures condom access at the estimated time of conception, while the groups are identified by age at birth, so that the diffusion coefficient for (e.g.) 19 year olds illustrates how the birth rate for 19-year-old women (who are generally too old to attend high school) changes depending on whether these women had school-condom access at the time of conception (which would typically be when these women were 18 years old, and potentially still in school). The results show strong and significant effects for the middle age groups. ${ }^{18}$ Further, the estimates become insignificant as women age out of high school, providing evidence that the impacts of school diffusion are limited to women of high-school-going age.

The appendix also shows two additional results. First, Appendix Table 2 gives results dropping each treatment county one-by-one, showing that the main result is not driven by any particular county. Next, Appendix Figure 1 provides a robustness test where we take the diffusion profile for each of our 22 treatment counties, and, without replacement, randomly assign the treatment profile to another of the 396 counties in the data. We then estimate the diffusion coefficient generated from this random assignment exercise 1,000 times using the baseline specification in Table 3, and provide a histogram of the resulting distribution in the figure. As expected, the distribution is centered around zero and symmetric, and the actual coefficient value falls in the 99th percentile of the distribution.

\footnotetext{
17 These estimates assume that there is no "spillover" from condom access in one district to other teens in a county. If there is spillover, than our measure of diffusion is too small, and the implied effect is too big. In a hypothetical extreme case of full spillover, where one district in a county offering condoms means all high-school-aged teens in a county have access (including unenrolled teens), a dummy variable for access would be appropriate. Redoing the baseline estimate using a dummy variable accordingly produces a smaller coefficient of 0.035 [se $=0.22$ ].

${ }^{18}$ Results using birth rates in levels give effects similar to the level effects suggested here, although the estimates are sometimes less precise when quadratic or cubic trends are used.
} 


\section{Contextual Factors and Channels}

Our finding of an increase in fertility in response to improved access to contraception contrasts with the great majority of the literature on the effects of other contraceptive methods. While our results may be surprising given this context, social scientists and policy-makers alike have long raised this possibility for condoms. One possible story, of course, is that condom provision condoned or otherwise encouraged risky sexual behavior. ${ }^{19}$ While the literature on this topic has certain flaws noted earlier, we note that there is essentially unanimity in the absence of support for this explanation. We discuss this possibility more below.

A second possible explanation for our fertility results is that school condom programs may have increased failure rates by encouraging substitution from other types of contraception, a possibility raised by Blake et al. (2003). There are two types of women who could be marginal in the decision between the condom and another method. First, sexually active teens who had been using a method such as the Pill could switch to the now freely-available condom. Second, young women who have never used any method (perhaps initiating intercourse for the first time) could choose to adopt the condom rather than another method. As condoms have high failure rates relative to most other contraception, this could cause an increase in teen pregnancy and births. Ott et al. (2002) document that teenage women rarely combine condoms with other methods of contraception, but instead "trade off between hormonal contraceptives and condoms according to partner type and perceived risk." Kearney and Levine (2015) also document that dual-use of contraception was much lower in the mid 1990s than in the late 2000s.

As a back-of-the envelope take on whether this channel could plausibly account for these results, suppose that condom use partially crowded out use of oral contraception. Based on a pregnancy risk for condoms of 18\% within the first year of typical use (for all women) versus $9 \%$ for the Pill, and assuming continued use for a year (although the percent of women continuing condom use is lower than that for the Pill), then about 5 teenage girls out of 100 using the condom instead of the pill could be sufficient to explain the increase in births we see in Table 2. (The risk rates are from Trussell, 2011). This calculation is intentionally simple and ignores other potential channels. But this calculation indicates that even if condom programs had negligible changes on sexual activity

\footnotetext{
${ }^{19}$ Arcidacono, Khwaja, and Lijing (2012) develop a dynamic discrete-choice model in which access to contraception decreases fertility in the short run but increases it in the long run through habit persistence. Since we document shortrun impacts here, this is likely a less-relevant channel for our estimates.
} 
overall, a modest crowd-out effect would be sufficient to produce the findings here. We again discuss this channel more below.

A third potential explanation for a positive fertility effect is raised by the Kirby et al. (1999) study. This study, which is noteworthy given its use of (a) a relatively large number of schools in the treatment group, (b) a nationally-based sample of control schools, (c) data both pre- and postintervention, and (d) data on both condom and other contraceptive use, found that condom use fell with diffusion. To explain this result, the authors note that condoms in their setting were provided without mandatory counseling (in baskets), and that this provision without counseling may have created an unexpected effect wherein counselors or other health-center officials responded to condom provision by turning their attention away from promoting condom use. This shift in attention, aside from any substitution effect, may have impacted the quality and quantity of teen contraceptive use. Programs without mandated counseling thus may have created a moral hazard problem in that they unintentionally disincentivized school personnel from promoting contraceptive use or other conduct discouraging conception. ${ }^{20}$

The Kirby et al. study thus highlights the potentially critical role of contextual factors such as mandatory counseling. In addition to the potential for moral hazard, mandatory counseling (or "counseling" for short) could alter the effects of condoms in other ways. Because counseling programs commonly promote abstinence and other safe sexual practices, counseling might discourage risky sexual activity that otherwise would be condoned by the presence of condoms in schools (or at least educate students on how to use condoms effectively or promote the use of dual methods). ${ }^{21}$ In this case, fertility increases would be driven by schools offering condoms without counseling. Also, if condom distribution raises fertility by generating substitution away from effective but relatively costly options like the Pill, we might expect to see less of this substitutionbased fertility increase in districts with mandated counseling if counseling increases the effort cost of acquiring condoms. This again would lead to higher fertility in non-counseling settings. On the other hand, if counseling emphasized the effectiveness of condoms in protecting against STIs, we

\footnotetext{
${ }^{20}$ School condom programs could also generate this type of moral-hazard problem among personnel at neighborhood clinics or other community agencies.

21 As discussed earlier, the evidence on the effects of sex education programs is mixed, but some programs have been shown to decrease risky sexual behaviors (Kirby, 2001; Toups and Holmes, 2002; Kirby et al. 2007). We also note that individual counseling to teenagers who are proactively trying to obtain condoms may work differently from other curriculum-based interventions. Kirby (2007, chapter 8) reviews several studies on teenage reproductive-health programs in clinics. He concludes that research is "remarkably" consistent in documenting the potential positive effects of individualized counseling programs in promoting sexual health.
} 
could see more substitution towards condoms and therefore more teen pregnancy in districts with counseling.

In Table 5 we explore the role of mandatory counseling in our results by including (a) a variable measuring diffusion among counties housing any condom program where counseling was mandated, and set to zero otherwise (that is, we interact our continuous diffusion variable with a dummy for whether a county housed any condom program mandating counseling), and (b) a similar variable measuring diffusion when counseling was not mandated and set to zero otherwise. ${ }^{22}$ There are a number of both types of county. ${ }^{23}$ The first column in Table 5 redoes the baseline estimate from Table 3, but interacts the treatment effect with a pair of dummy variables for (a) whether a county housed a counseling condom program and (b) whether a county housed a non-counseling condom program. Column 1 uses linear trends, column 2 adds quadratic trends. The results in the two columns indicate that the teen birth rate significantly increased when condoms were introduced without mandated counseling, but decreased when counseling was mandated. The effects are large in magnitude-indeed, somewhat larger (in absolute value) than the baseline effects shown in Table 3 earlier. The bottom of the table includes F statistics from Wald tests that the two coefficients on condom access are equal; the hypothesis that the coefficients are equal (that is, the hypothesis that condom access has the same fertility impact in both counseling and non-counseling communities) is rejected at the 1 percent level. The results indicate that the increase in fertility observed earlier was driven by counties where counseling was not mandated.

The next two columns include the 20 -to-24 year-old birth rate in each county as a control, so that the effect of condom programs can be identified from variation between each age group and each type of program. As before, counties without counseling see an increase in the teen birth rate. Looking at counties with counseling, however, the effect on the teen birth rate is notably smaller

\footnotetext{
22 The method of condom distribution can be "bundled" with the counseling requirement. Distribution is more likely to be handled by a nurse or other health professional in counseling districts, and less likely to be done with a basket or vending machine. Given the belief at the time of the potential importance of counseling, the relatively small number of basket-or-vending-machine-based programs, the different roles counseling could have in understanding mechanisms, the availability of data on counseling mandates, and the policy relevance of this aspect of diffusion, we focus on counseling here.

${ }^{23}$ See Table 1 for how counties are classified. We code Los Angeles as non-counseling as its two non-counseling districts (Los Angeles Unified and Santa Monica Unified) are much larger than its counseling district (Culver City Unified). Also, two other counties housing counseling programs also housed programs without counseling (Middlesex and Worcester); simply dropping Los Angeles, Middlesex, and Worcester from the sample yields similar results to those here. We code San Francisco as a counseling county based on the discussion in Asimov (1992b), although the (pre adoption) comments in Asimov (1991) suggest counseling may have varied. Recoding San Francisco as non-counseling produces similar results. Results using levels rather than logs are also qualitatively similar.
} 
than before and is now statistically insignificant. However, despite the lack of precision, the coefficients continue to suggest an economically significant difference in the effects of condom access across the two types of counties, and again a Wald test of the hypothesis of equality of the coefficients is rejected in both column 3 and column 4 at the 5 -percent level.

These regressions impose the restriction that the right-hand side controls in the regressions impact teen fertility in similar ways across counties. But if among counties with condom access programs there is some other important characteristic which generates variation in birth rates, and this characteristic differs between counties with access and other counties, then the variation observed between counseling and non-counseling might be driven not by the presence of counseling, but rather might reflect variation along this other characteristic. The last two columns investigate this possibility by redoing the estimates in columns 3 and 4 , but here, the right-hand-side covariates in $\mathrm{X}_{\mathrm{ct}}$ from equation (1) are interacted with a dummy for whether a county ever houses a condom-access program. Changes in either coefficient would be evidence that the differential behavior of a particular type of county could in part stem from differential responses to the other covariates. In fact, that is not the case. The precision of the estimates (and the Wald statistics) is somewhat lower, which is unsurprising as the set of covariates now includes additional regressors that are mechanically correlated with the treatment variables. ${ }^{24}$ But this notwithstanding, the estimates are close to those in columns (3) and (4). ${ }^{25}$

Figure 2 presents further evidence on the role of counseling. The figure shows county-bycounty estimates of condom diffusion, grouped by counseling status. Each point in the figure is from a separate regression. Each regression is based on column 2 in Table 3, except that only a single treatment county is included. ${ }^{26}$ Since the estimated effects are off of a small base and will be identified by comparing responses in a single county to the control group, we report results from the 16 regressions that use treatment counties with more than 10,000 females ages 15 to 19 in 1990. The dashed lines indicate $95 \%$ confidence intervals.

The picture shows a remarkably consistent pattern where every large treatment county

\footnotetext{
24 One might wonder about whether the additional interacted covariates are themselves typically significant. Of the 22 additional covariates in columns 5 and 6 in the Table (11 in each regression), none are significant in both regressions and in fact only three are statistically significant at the 10 percent level (that is, $p<0.10$ ), and none are significant at the 5 percent level $(p<0.05)$ or better.

${ }^{25}$ One could also apply this robustness test to the baseline regressions earlier that do not disaggregate counties by counseling. Doing so produces qualitatively similar results; for example adding these interaction terms to the estimate in column 2 of Table 3 produces a coefficient of 0.088 [se $=0.058$ ]

${ }^{26}$ Using column 1 in Table 3 produces similar results.
} 
lacking counseling sees an increase in fertility following diffusion (although in Bronx and Kings counties the coefficients are insignificant, with confidence intervals of $[-0.06,0.09] \&[-0.004,0.13]$, respectively). Clearly, the results for non-counseling counties are not driven by any one county. Also following the earlier results, the counseling estimates are suggestive of a decline in fertility on average but are noisier, with one county (New Haven) even suggesting a large (but imprecisely estimated) increase. As before the picture shows evidence of increases in birth rates in noncounseling counties, and less-robust evidence of declines for counseling counties.

Table 6 gives a final account of the robustness of this result. The estimates in Table 6 address the concern that there may be heterogeneity within diffusing counties that impacts the efficacy of condom programs. For example, perhaps wealthy counties gaining condoms responded differently than poorer counties, and perhaps wealthy counties were more likely to adopt counseling. In that case, the results of Table 5 might confound the differential effect of counseling with the differential effect of income. The first column in the table repeats the baseline regression in Table 5. In the next column of Table 6 , a new regressor is added that interacts the diffusion covariate with a dummy for whether or not a county has above-average per-capita income (where the average is calculated only among diffusing counties). If the variation found in Table 5 is driven not by counseling itself, but rather reflects the fact that high income counties respond to condoms differently, then the inclusion of this new interaction term could substantially alter the estimates. (Note that a below-average interaction term cannot be included, as it would be collinear with the other three diffusion variables.) In fact, the new coefficient is small and insignificant and the other coefficients are unchanged, suggesting that the variation between counseling and non-counseling counties in the baseline estimates was not an artifact of constraining richer counties gaining condoms to have similar effects as poorer counties. The rest of the table confirms this result using interactions with population size and race-the variation in efficacy appears to be driven by counseling, rather than some other characteristic of counties. As in Table 5, results with quadratic trends are similar but the significance of counseling estimates can be lower, while in this case the non-counseling estimates are more robust (results with these additional controls are reported below the table).

The evidence clearly suggests that counseling matters. However, several of our proposed mechanisms are consistent with these results. For example, counseling might discourage risky sexual behavior otherwise encouraged by diffusion; or, even if risky sexual behavior were unchanged, 
counseling might mitigate the substitution-between-contraception story mentioned earlier (e.g., by educating students about dual-use). If one had data on teen sexual activity, one could look at this as an outcome variable to further explore why fertility increased and why it did so differentially by counseling status. Unfortunately, we were unable to find a data set that measured sexual activity or contraceptive use in this time period with usable geographic variation. ${ }^{27}$ Instead, we consider this possibility by using STI rates as an outcome variable.

Our data are from the Centers for Disease Control's Sexually Transmitted Disease Surveillance Reports from 1989 to 1999. Data are available by gender for cities with populations over 200,000. The rate of STIs can serve as a proxy for risky sexual behavior. Furthermore, results on condom diffusion and STIs are of interest independent from questions on teen fertility, given that the main objective of the programs was to reduce these infections. Because we only have data for cities over 200,000 , more than half of the treatment districts were dropped from this analysis. ${ }^{28}$ We also have to map city-level STI data to counties, which we do by using the measure of program access for the county in which the city is primarily located. In the end, we have 59 cities including seven cities from treatment counties. ${ }^{29}$

STI data are available for syphilis, gonorrhea, and chlamydia, but data on chlamydia are missing for several cities until the early 1990s and syphilis has a very low incidence (gonorrhea rates among women were more than ten times higher than rates of syphilis during this period). Gonorrhea symptoms also typically appear sooner than syphilis symptoms. We therefore focus on results for gonorrhea; results are presented in Table 7. First, we show that we are able to replicate our results for teen births using this more restricted sample. Using the same specification as in column 1 of Table 3, the coefficient on the treatment measure is 0.123 (se=0.038), compared to 0.127 ( $\mathrm{se}=0.047$ ), and we continue to find that the positive fertility effect is driven by counties without counseling. ${ }^{30}$ In columns (3) and (4), the dependent variable is the log of the gonorrhea rate

\footnotetext{
${ }^{27}$ For example, the Youth Risk Behavior Surveillance System does not begin until 1991, the Behavioral Risk Factor Surveillance System only surveys women and men age 18 and older, and the National Survey of Family Growth is too small given our requirements for geographic variation. We considered using birth certificate data on herpes cases among teen mothers (the only sexually transmitted infection recorded on birth certificates), but unfortunately for our purposes, the incidence of herpes on the birth certificates was too low to permit this analysis.

${ }^{28}$ The smaller sample does allow us to use the Evans, Garthwaite, and Moore (2012) data to include controls for the arrival of the crack epidemic.

${ }^{29}$ The treatment cities with counseling are Philadelphia, Portland, San Francisco, and Washington, D.C. The treatment cities without counseling are Los Angeles, New York City, and Seattle.

${ }^{30}$ Results using quadratic trends are unsurprisingly less precise here given the smaller sample and time frame (this loss in precision holds for both the fertility estimates and the STI estimates in the Table 7 sample).
} 
for women. The coefficient on the treatment indicator is 0.747 , which is statistically significant at the $10 \%$ level. Given the incidence of gonorrhea among women, this corresponds to an additional 2.43 cases per 1,000 women. When we consider the effects of counseling and non-counseling programs separately, we show that the effects are driven by the non-counseling programs. The coefficient for counseling programs is 0.264 (se=0.495), while the coefficient for non-counseling programs is 0.923 (se=0.384), and the null hypothesis that the coefficients are the same is rejected at the $5 \%$ level.

These results suggest that risky sexual behavior may have increased in areas without counseling programs. We do not see this in districts with required counseling, potentially because counseling effectively discourages these behaviors or promotes effective use or dual-use. The results also suggest that programs without counseling were unsuccessful in reducing the transmission of at least one STI. However, we urge caution in interpreting these results. STI rates for cities are not available by age, so we are unable to isolate the effects for teenagers or include the rates for other age groups as a control. ${ }^{31}$ As can be seen in Tables 3 and 5, the results for teen births were attenuated when rates for women age 20-24 were included as a control. The results are also imprecise given our low number of treatment cities, particularly when considering counseling (four programs) and non-counseling (three programs) separately. Finally, because the STI series by gender do not begin until 1989, we do not have a long pre-period for some of our treatment cities. ${ }^{32}$

Overall, Tables 5 and 6 and Figure 2 show that the increase in teen fertility is driven by counties where condoms are provided without mandatory counseling and that the fertility response is significantly different in these counties compared to counties that mandated counseling. In fact, the results suggest that programs with counseling may have seen no change or perhaps a decline in teen fertility. Results using STI rates also indicate increases in these rates in places providing condoms without counseling.

Taken together, what do our results and the existing literature suggest about the contexts and channels that mediate the effects of condom access? Our simple back-of-the-envelope calculation suggested that substitution to condoms from other contraception could drive our main fertility results. We raised the possibility that this type of substitution (and thus the increase in

\footnotetext{
31 Teenagers do account for a significant portion of all gonorrhea cases. In 1995, the gonorrhea rate for women age $15-$ 19 was 839.7 per 100,000 women, which was the highest for any age group and six times higher than the overall rate of 139.6 (CDC 1996).

32 We have focused on rates for women, since our fertility measure is also constructed for women. We find no effects of condom distribution programs on gonorrhea rates for men.
} 
fertility) may have been greater in counseling districts if counseling promoted substitution by, for example, emphasizing the effectiveness of condoms in preventing STIs. However, that would be inconsistent with the results in Tables 5 and 6 and Figure 2. Those results are consistent with a story in which counseling prevented substitution toward condoms by raising the effort cost of obtaining them, but this story is not consistent with our STI estimates in Table 7 (since we do not see a relative increase in STI rates in counseling counties) or the findings in the Kirby et al. (1999) paper. A story in which condom programs encourage substitution toward condoms, but counseling leads toward more reliable condom use or to the use of dual methods, is consistent with our differential fertility and STI results, but not with the Kirby et al. (1999) paper. Similarly, an increase in sexual activity prompted by condom access would fit our differential fertility and STI results if counseling discouraged risky sexual behavior, but is less compatible with extant research.

Finally, it may be that programs without counseling introduced an unexpected effect wherein school officials or counselors responded to condom provision by turning their attention away from issues surrounding teen pregnancy — the possibility raised by Kirby et al. (1999) in considering their own paradoxical finding of access lowering condom use. This explanation is consistent with (a) most prior studies on condom diffusion and the constancy of sexual behavior, (b) our fertility results, (c) the differential effect by counseling that we identify here, (d) the STI results, and (e) the paradoxical results in the Kirby et al. study; in fact it is the only channel to fit with all these pieces of evidence.

While this explanation fits with the available evidence, we caution that not all of this evidence is necessarily sacrosanct. For example, as noted before, prior work on condoms and sexual activity has faced methodological limitations, and the STI results above should be taken as suggestive. Further, it is certainly possible that some of these different channels may play a role simultaneously - they are not mutually exclusive. But clearly the results above indicate that contextual factors are of first-order importance when providing condoms - a critically important result both for policy makers and for scholars interested in considering how historic episodes of contraception diffusion (e.g., the Pill) may extend to different eras and contexts.

\section{Conclusions}

In this paper, we show that the introduction of condom access programs in schools is associated with an increase in teenage fertility. This result is driven by schools that provided 
condoms without mandating counseling. The effects are reasonably large in magnitude and contrast with the implications of prior work on access to oral contraception in the 1960s and 1970s and on more recent work on the effects of LARCs. As Martha Bailey (2006) points out in her paper on the long-term effects of oral contraception, the Pill was revolutionary because it 1) was used by women, 2) was not used at the time of intercourse, and 3) was much more effective than previous methods. The LARCs studied by Lindo and Packham (2015) also have these three features, and are in fact even more effective than the Pill. The condom, on the other hand, has none of these advantages. In this sense, our estimates help show how the likely effects of contraception access vary across the full range of available methods.

One shortcoming of our paper is the lack of stronger evidence on mechanisms, due to the lack of adequate data on sexual behaviors at the county level for these cohorts. However, our results on fertility are well-identified and robust, and are an important finding even in the absence of clear evidence on mechanisms. Our results also provide clear evidence against the adequacy of some explanations, such as a substitution-of-contraception story, to fully explain the increase in fertility here. Further, evidence that contraception diffusion in this case increased fertility is of clear importance. If one were to simply consult the prior literature on other methods of contraception to make policy recommendations about condom distribution programs, one would find little reason to be concerned about unintended effects on teen pregnancy. Our paper suggests that this could be very misleading.

We also recognize that we have estimated the effects of condom distribution in schools in a specific context - primarily large urban districts, in the early 1990s. The time period is especially relevant. Overall, teenagers today are less likely to engage in sexual activity and are less likely to become pregnant. Teens also have increased access to a wider range of contraceptives, and are more likely to use dual methods (Kearney and Levine 2015). Condom distribution programs in today's schools may not have the same effects as those shown here. Policy makers should therefore use caution in generalizing our results to predict the effects of condom distribution programs for today's teens. But again, our results suggest they should be equally cautious about generalizing results from an existing literature that is based on access to other methods of contraception.

Our work also informs the discussion about the causes of the notable decline in teenage childbearing during the 1990s. Several explanations for this decline have been proposed, including incarceration (Mechoulan, 2011), welfare reform (Lopoo and DeLeire, 2006), pregnancy prevention 
messaging campaigns (Martin et al., 2012) or the improving economy (Colen, Geronimus, Phipps, 2006; Arkes, and Klerman, 2009). Some observers, especially Santelli and Melnikas (2010) have noted that the decline in teen fertility coincides with the rise of condom access, but their observation goes no further than a discussion of overall trends. Our work shows that, in fact, condom accessat least through schools_ _ did not play a role in the decline in teen fertility in the 1990s. 


\section{References}

Allen, Joseph, Susan Philliber, Scott Herrling, and Gabriel Kuperminc. 1997. "Preventing Teen Pregnancy and Academic Failure: Experimental Evaluation of a Developmentally Based Approach," Child Development 68(4): 729-742.

American Academy of Pediatrics. 2013. “Condom Use by Adolescents,” Pediatrics 132(5): 973-981.

Ananat, Elizabeth, and Daniel Hungerman. 2012. "The Power of the Pill for the Next Generation: Oral Contraception's Effects on Fertility, Abortion, and Maternal and Child Characteristics." Review of Economics and Statistics 94: 37-51.

Arcidiacono, Peter, Ahmed Khwaja and Lijing Ouyang. 2012. "Habit Persistence and Teen Sex: Could Increased Access to Contraception have Unintended Consequences for Teen Pregnancies?” Journal of Business and Economic Statistics 30(2): 312-325.

Arkes, Jeremy, and Jacob Klerman. 2009. "Understanding the Link Between the Economy and Teenage Sexual Behavior and Fertility Outcomes." Journal of Population Economics 22: 517-536.

Ashcraft, Adam and Kevin Lang. 2006. "The Consequences of Teenage Childbearing." NBER Working Paper 12485.

Asimov, Nanette. 1991. "Free Condoms Distributed to SF Teenagers," San Francisco Chronicle, February 15.

Asimov, Nanette. 1992a. “Condom program starts May 4” San Francisco Chronicle, April 8. Asimov, Nanette. 1992b. "Condoms Promised at All S. F. High Schools," San Francisco Chronicle, December 2.

Bailey, Martha J. 2006. "More Power to the Pill: The Impact of Contraceptive Freedom on Women's Life Cycle Labor Supply.” Quarterly Journal of Economics 121: 289-320.

Banks, Sandy. 1991. "School Officials back Plan to Make Condoms Available," Los Angeles Times, September 27.

Bidgood, Jess. 2013. "Board to Vote on Condoms in Boston Schoos," The New York Times, June 
18.

Blake, Susan, Rebecca Ledsky, Carol Goodenow, Richard Sawyer, David Lohrmann, and Richard Windsor. 2003. "Condom Availability Programs in Massachusetts High Schools: Relationships with Condom Use and Sexual Behavior.” American Journal of Public Health 93: 955-962.

Boonstra, Heather. 2014. "What is Behind the Declines in Teen Pregnancy Rates?” Guttmacher Policy Review 17(3): 15-21.

Brown, Nancy, Michelle Pennylegion, Pamela Hillard. 1997. “A Process Evaluation of Condom Availability in the Seattle, Washington Public Schools." Journal of School Health 67: 336-340.

Centers for Disease Control. 1996. Sexually Transmitted Disease Surveillance, 1995. Atlanta: CDC.

Chicago Tribune. 2014. "CPS to Expand Free Condom Program to 24 Schools." March 19.

Cohen, Deborah A. 1999. "Condom Availability for HIV/STD Prevention." AIDS Patient Care and STDs, 13(12), 731-737.

Colen, Cynthia G. Arline Geronimus, Maureen Phipps. 2006. "Getting a Piece of the Pie? The Economic Boom of the 1990s and Declining Teen Birth Rates in the United States.” Social Science \& Medicine 63: 1531-1545.

Durrance, Christine. 2013. “The Effects of Increased Access to Emergency Contraception on Sexually Transmitted Disease and Abortion Rates.” Economic Inquiry 51(3): 1682-1695.

Evans, William, Craig Garthwaite, and Timothy J. Moore. 2012. “The White/Black Educational Gap, Stalled Progress, and the Long Term Consequences of the Emergence of Crack Cocaine Markets.” NBER Working Paper 18437.

Furstenberg, Frank. 1976. “The Social Consequences of Teenage Parenthood.” Family Planning Perspectives 8(4): 148-151, 151-164.

Furstenberg, Frank, Lynne Geitz, Julien Teitler and Christopher Weiss. 1997. "Does Condom Availability Make a Difference? An Evaluation of Philadelphia's Health Resource Centers.” Family Planning Perspectives 29: 123-127. 
Geronimus, Arline and Sanders Korenman. 1992. "The Socioeconomic Consequences of Teen Childbearing Reconsidered." The Quarterly Joumal of Economics, 107(4): 1187-1214.

Girma, Sourafel and David Paton. 2011. “The Impact of Emergency Birth Control on Teen Pregnancy and STIs." Journal of Health Economics, 30(2): 373-380.

Goldin, Claudia, and Lawrence F. Katz. 2002. "The Power of the Pill: Oral Contraceptives and Women's Career and Marriage Decisions," Journal of Political Economy 110: 730-770.

Goldstein, Amy, and Steve Bates. 1993. "Alexandrea to Fight AIDS with Condoms in School; Grades 9-12 First to be Targeted in VA," The Washington Post, June 19.

Guldi, Melanie. 2008. "Fertility Effects of Abortion and Birth Control Pill Access for Minors," Demography 45: 817-827.

Hoffman, Saul D. 1998. “Teenage Childbearing Is Not So Bad After All...Or Is It? A Review of the New Literature." Family Planning Perspectives 30(5): 236-239+243.

Hughes, Mary Elizabeth, Frank F. Furstenberg Jr., and Julien O. Teitler. 1995. "The Impact of an Increase in Family Planning Services on the Teenage Population of Philadelphia," Family Planning Perspectives 27(2): 60-65+78.

Johnson, Johan. 1998. A Battle of Values: The Condom Controversy in New York City Public Schools. PhD Dissertation.

Joyce, Theodore, Robert Kaestner, and Silvie Colman. 2006. "Changes in Abortions and Births and the Texas Parental Notification Law." New England Journal of Medicine, 354(10): 1031-1038.

Kahn, Joan, and Kay Anderson. 1992. “Intergenerational Patterns of Teenage Fertility,” Demography 29(1): 39-57.

Kearney, Melissa, and Phillip Levine. 2012. "Why is the Teen Birth Rate in the United States so High and Why Does it Matter?" Journal of Economic Perspectives 26(2): 141-166.

Kearney, Melissa, and Phillip Levine. 2015. "Investigating Recent Trends in the U.S. Teen Birth Rate," Journal of Health Economics 41: 15-29. 
Kirby, Douglas. 2001. Emerging Answers: Research Findings on Programs to Reduce Teen Pregnancy. Washington DC: the National Campaign to Prevent Teen Pregnancy.

Kirby, Douglas. 2002. "The Impacts of Schools and School Programs Upon Adolescent Sexual Behavior," in The Journal of Sex Research 39(1): 27-33.

Kirby, Douglas, 2007. Emerging Answers: Research Findings on Programs to Reduce Teen Pregnancy and Sexually Transmitted Diseases. Washington DC: The National Campaign to Prevent Teen and Unplanned Pregnancy.

Kirby, Douglas, Richard P. Barth, Nancy Leland and Joyce V. Fetro. 1991. "Reducing the Risk: Impact of a New Curriculum on Sexual Risk-Taking," Family Planning Perspectives 23(6): 253-263.

Kirby, Douglas, Nancy Brener, Nancy Brown, Nancy Peterfreund, Pamela Hillard, and Ron Harrist. 1999. "The Impact of Condom Distribution in Seattle Schools on Sexual Behavior and Condom Use." American Journal of Public Health 89: 182-187.

Kirby, Douglas, and Nancy Brown. 1996. "Condom Availability Programs in U.S. Schools." Family Planning Perspectives 28: 196-202.

Kirby, Douglas, and Karin Coyle. 1997. "School-Based Programs to Reduce Sexual Risk-Taking Behavior." Children and Youth Services Review, 19(5): 415-436.

Kirby, Douglas, Meg Korpi, Carla Adivi, and Jennifer Weissman. 1997. “An Impact Evaluation of Project SNAPP: An AIDs and Pregnancy Prevention Middle School Program," AIDS Education and Prevention 9(1, Suppl): 44-61.

Kirby, D. B., Laris, B.A., Rolleri, L.A. 2007. "Sex and HIV Education Programs: Their Impact on Sexual behaviors of Young People Throught the World." Journal of Adolescent Health, 40(3): 2062107.

Leitman, Robert, Erich Kramer, and Humphrey Taylor. 1993. “A Survey of Condom Programs," in: Sarah Samuels and Mark Smith (eds.) Condoms in the Schools. Menlo Park CA: Kaiser Family Foundation.

Lewin, Tamar. 1991. "Studies on Teen-Age Sex Cloud Condom Debate," The New York Times, 
February 8.

Lieberman, Lisa, Heather Gray, Megan Wier, Renee Fiorentino, and Patricia Maloney. 2000.

"Long-Term Outcomes of an Abstinence-Based, Small-Group Pregnancy Prevention Program in Newy York City Schools." Family Planning Perspectives 32(5): 237-245.

Lindo, Jason, and Analisa Packham. 2015. "How Much Can Expanding Access to Long-Acting Reversible Contraceptives Reduce Teen Birth Rates?” NBER Working Paper 21275.

Lopoo, Leonard M., and Thomas DeLeire. 2006. "Did Welfare Reform Influence the Fertility of Young Teens?” Journal of Policy Analysis and Management 25: 275-298.

Lovenheim, Michael, Randall Reback, and Leigh Wedenoja. 2014. "How Does Access to Health Care Affect Health and Education? Evidence from School-based Health Center Openings,” Working paper.

Martin, Joyce A., Brady E. Hamilton, Stephanie J. Ventura, Michelle J. K. Osterman, Elizabeth C. Wilson, and T. J. Mathews. 2012. "Births: Final Data for 2010.” National Vital Statistics Reports, 61(1). Hyattsville, MD: National Center for Health Statistics.

Martinez-Donate, Melbourne Hovell, Jennifer Zellner, Carol Sipan, Elaine Blumberg, and Claudia Carrizosa. 2004. "Evaluation of Two School Based HIV Prevention Interventions in the Border City of Tijuana, Mexico.” The Journal of Sex Research 41: 267-278.

Mechoulan, Stéphane. 2011. “The External Effects of Black Male Incarceration on Black Females.” Journal of Labor Economics 29: 1-35.

National Institute for Health and Care Excellence. 2014. “Contraceptive Services with a Focus on Young People up to the Age of 25," NICE Public Health Guidance 51, accessed on 12/12/2014 at guidance.nice.org.uk/ph51 .

Nealon, Patricia. 1993. “Condoms: A Fact of Life in Many Mass. Schools,” Boston Globe, March 5.

Ott, Mary A., Nancy E. Adler, Susan G. Millstein, Jeanne M. Tschann, and Jonathan M. Ellen. 2002. "The trade-off between hormonal contraceptives and condoms among adolescents." Perspectives on sexual and reproductive health, 6-14. 
Pantano, Juan. 2007. "Unwanted Fertility, Contraceptive Technology, and Crime: Exploiting a Natural Experiment in Access to the Pill.” California Center for Population Research working paper no. $028-07$

Paton, David. 2002. “The Economics of Family Planning and Underage Conceptions.” Journal of Health Economics 21(2): 207-225.

Philliber, Susan, Jacqueline Williams Kaye, Scott Herrling and Emily West. 2002. "Preventing Pregnancy and Improving Health Care Access Among Teenagers: An Evaluation of the Children's Aid Society-Carrera Program.” Perspectives on Sexual and Reproductive Health 34(5): 224-251.

Rafferty, Yvonne and Alice Radosh. 2000. “AIDS Prevention and Condom Availability in an Urban School System: Facilitating Factors and Programme Challenges," Health Education Journal 59: $50-68$.

Ramos, P. S. 1996. "The condom controversy in the public schools: Respecting a minor's right of privacy." University of Pennsylvania Law Review: 149-192.

Samuels, Sarah and Mark Smith, eds. 1993. Condoms in the Schools. Menlo Park CA: Kaiser Family Foundation.

Santelli, John and Andrea Melnikas. 2010. "Teen Fertility in Transition: Recent and Historic Trends in the United States." Annual Review of Public Health 31: 371-383.

Schuster, Mark, Robert Bell, Sandra Berry, and David Kanouse. 1998. "Impact of a High School Condom Availability Program on Sexual Attitudes and Behaviors," Family Planning Perspectives 30(2): 67-88.

Tan, Sandra. 2014. “'Condom Availability' Weighed for High Schools.” Buffalo News, October 1. Taylor, Paul. 1991. "High School Clinic: Case Study in Sexual risk; In Rural Florida Town, Impact of Offering Free Condoms to Teenagers Remains Unclear," The Washington Post, March 10.

Tillman, Leroy. 1992. "Washington, D.C., to Give Condoms in Schools to Fight AIDS," Associated Press Report, May 12. 
Toups, M. L. and Holmes, W. R. 2002. "Effectiveness of Abstinence-Based Sex Education Curricula: A Review." Counseling and Values, 46: 237-240.

Trussell, James. 1976. “Economic Consequences of Teenage Childbearing." Family Planning Perspectives, 8(4): 184-190.

Trussell, James. 2011. "Contraceptive Efficacy." In Hatcher, Trussell, Nelson, Cates, Kowal, Policar (eds) Contraceptive Technology: Twentieth Revised Edition. New York NY: Ardent Media.

Wretzel, Sharon, Paul Visintainer, and Laura Pinkston Koenigs. 2011. "Condom Availability Program in an Inner City Public School: Effect on the Rates of Gonorrhea and Chlamydia Infection," Journal of Adolescent Health 49: 324-326. 
Table 1: School Districts with Condom Diffusion Programs

\begin{tabular}{|c|c|c|c|c|}
\hline District & County & Students (1990) & Year & Counseling \\
\hline Adams County School District 14 & Adams, CO & 1,196 & 1989 & Yes \\
\hline Baltimore City Public School System & Baltimore City, MD & 4,431 & 1990 & Yes \\
\hline Cambridge Public School District & Middlesex, MA & 2,078 & 1990 & Yes \\
\hline New York City Public Schools & $\begin{array}{l}\text { Bronx, Kings, New York, } \\
\text { Queens, Richmond, NY }\end{array}$ & 250,033 & 1991 & No \\
\hline Brookline Public School District & Norfolk, MA & 1,793 & 1992 & Yes \\
\hline Culver City Unified School District & Los Angeles, CA & 1,325 & 1992 & Yes \\
\hline District of Columbia Public Schools & Washington, D.C. & 14,275 & 1992 & Yes \\
\hline Falmouth School District & Barnstable, MA & 1,292 & 1992 & No \\
\hline LA-Unified School District & Los Angeles, CA & 163,435 & 1992 & No \\
\hline Lincoln-Sudbury School District & Middlesex, MA & 931 & 1992 & No \\
\hline Newton Public Schools & Middlesex, MA & 2,668 & 1992 & Yes \\
\hline Portland Public Schools & Multnomah, OR & 12,776 & 1992 & Yes \\
\hline Portsmouth School District & Rockingham, NH & 1,024 & 1992 & Yes \\
\hline $\begin{array}{l}\text { Public schools of Northborough and } \\
\text { Southborough }\end{array}$ & Worcester, MA & 854 & 1992 & Yes \\
\hline San Francisco Unified School District & San Francisco, CA & 19,589 & $1992 *$ & Yes \\
\hline Santa Monica-Malibu Unified School District & Los Angeles, CA & 2,779 & 1992 & No \\
\hline School District of Philadelphia & Philadelphia, PA & 19,443 & $1992^{\ddagger}$ & Yes \\
\hline Alexandria City Public Schools & Alexandria, VA & 2,551 & 1993 & Yes \\
\hline Amherst-Pelham Regional Public School District & Hampshire, MA & 1,004 & 1993 & No \\
\hline New Haven Public Schools & New Haven, CT & 1,470 & 1993 & Yes \\
\hline Seattle Public School District & King, WA & 10,854 & $1993^{\dagger}$ & No \\
\hline Wachusett Regional School District & Worcester, MA & 1,530 & 1993 & No \\
\hline
\end{tabular}


Table 2: Pre-Treatment Summary Statistics for Treatment and Control Counties

\begin{tabular}{lcc}
\hline & $\begin{array}{c}\text { Counties that Adopt a } \\
\text { Condom Program }\end{array}$ & $\begin{array}{c}\text { Counties that Do Not } \\
\text { Adopt a Condom } \\
\text { Program }\end{array}$ \\
\hline $\begin{array}{l}\text { Birthrate of Women 15 to 19 } \\
\text { (births per 1000 women) }\end{array}$ & 53.1 & 52.6 \\
Number of Women 15 to 19 & {$[29.2]$} & {$[21.2]$} \\
Fraction of Population Under 18 & 40,954 & 12,404 \\
& {$[62,234]$} & {$[11,833]$} \\
Fraction of Population Over 65 & 0.24 & 0.28 \\
Fraction White & {$[0.04]$} & {$[0.03]$} \\
& 0.13 & 0.11 \\
& {$[0.03]$} & {$[0.04]$} \\
Per-capita Income & 0.73 & 0.85 \\
& {$[0.22]$} & {$[0.12]$} \\
& 28,149 & 23,644 \\
Number of Observations & {$[7,570]$} & {$[4,714]$} \\
\hline
\end{tabular}

Table reports simple county-level averages for counties that ever adopt a school condom program (column 1) and counties that do not adopt a condom program (column 2). Standard deviations are in brackets. The number of county/year observations is given below the table. The data are for means for the years 1982 to 1989. 
Table 3: Condom Diffusion Programs and Teen Fertility

\begin{tabular}{|c|c|c|c|c|c|}
\hline & $\begin{array}{c}\text { Linear Trends } \\
\text { (1) }\end{array}$ & $\begin{array}{c}\text { Quadratic } \\
\text { Trends } \\
(1)\end{array}$ & $\begin{array}{c}\text { Cubic Trends } \\
\text { (1) }\end{array}$ & $\begin{array}{c}\text { Lead Effect } \\
(4)\end{array}$ & $\begin{array}{c}\text { With } 20-24 \\
\text { Birth rate } \\
\text { (5) }\end{array}$ \\
\hline Diffusion & $\begin{array}{c}0.127 \\
{[0.047]}\end{array}$ & $\begin{array}{c}0.096 \\
{[0.043]}\end{array}$ & $\begin{array}{c}0.122 \\
{[0.037]}\end{array}$ & $\begin{array}{c}0.112 \\
{[0.056]}\end{array}$ & $\begin{array}{c}0.100 \\
{[0.042]}\end{array}$ \\
\hline Lead of Diffusion & - & - & - & $\begin{array}{c}0.01 \\
{[0.031]}\end{array}$ & - \\
\hline RHS Controls & Yes & Yes & Yes & Yes & Yes \\
\hline Year Dummies & Yes & Yes & Yes & Yes & Yes \\
\hline County FEs & Yes & Yes & Yes & Yes & Yes \\
\hline County Trends & Linear & Quadratic & Cubic & Linear & Linear \\
\hline Observations & 7,498 & 7,498 & 7,498 & 6,706 & 7,498 \\
\hline R-squared & 0.982 & 0.988 & 0.991 & 0.983 & 0.986 \\
\hline
\end{tabular}

The dependent variable is the log of the birth rate among women ages 15 to19. Diffusion measures the fraction of high-school students in a county exposed to a district-wide condom access program. The mean of the dependent variable (in levels) is 5.4. Among counties with a condom program, the mean level of diffusion is 0.37 and the standard deviation is 0.29 . Standard errors are clustered by county. The regressions include 396 counties covering conceptions from 1982 through 2000. Month of conception is estimated by subtracting the reported gestation period from the birth month. Right-hand side controls include per-capital income, per capita Medicaid transfers, state unemployment insurance compensation per capita, total population in levels and logs, the fraction of the population Hispanic, fraction white, fraction under 18, the fraction poor and under 18, and the fraction over age 65. Regressions are weighted by the population of women ages 15 to 19 as of 1990 . The year that a condom program is adopted in a county is dropped from the sample. The last column adds the birth rate for women ages 20 to 24 , in $\operatorname{logs}$, as a control variable. 
Table 4: Results Across Age Groups

\begin{tabular}{|c|c|c|c|}
\hline & $\begin{array}{c}\text { Mean Birth } \\
\text { Rate (Levels) } \\
(1)\end{array}$ & $\begin{array}{c}\text { Linear } \\
\text { Trends } \\
(2)\end{array}$ & $\begin{array}{c}\text { Quadratic } \\
\text { Trends } \\
\text { (3) }\end{array}$ \\
\hline Diffusion: 15-to-19 Birth Rate & 5.41 & $\begin{array}{c}0.127 \\
{[0.047]}\end{array}$ & $\begin{array}{c}0.096 \\
{[0.043]}\end{array}$ \\
\hline Diffusion: 20-to-24 Birth Rate & 10.38 & $\begin{array}{c}0.045 \\
{[0.055]}\end{array}$ & $\begin{array}{c}-0.004 \\
{[0.052]}\end{array}$ \\
\hline Diffusion: 15-Year-old-Birth Rate & 1.65 & $\begin{array}{c}0.078 \\
{[0.057]}\end{array}$ & $\begin{array}{c}0.028 \\
{[0.074]}\end{array}$ \\
\hline Diffusion: 16-Year-old-Birth Rate & 3.47 & $\begin{array}{c}0.045 \\
{[0.057]}\end{array}$ & $\begin{array}{c}0.014 \\
{[0.064]}\end{array}$ \\
\hline Diffusion: 17-Year-old-Birth Rate & 5.50 & $\begin{array}{c}0.092 \\
{[0.061]}\end{array}$ & $\begin{array}{c}0.088 \\
{[0.052]}\end{array}$ \\
\hline Diffusion: 18-Year-old-Birth Rate & 7.26 & $\begin{array}{c}0.151 \\
{[0.054]}\end{array}$ & $\begin{array}{c}0.127 \\
{[0.053]}\end{array}$ \\
\hline Diffusion: 19-Year-old-Birth Rate & 8.18 & $\begin{array}{c}0.146 \\
{[0.055]}\end{array}$ & $\begin{array}{c}0.096 \\
{[0.047]}\end{array}$ \\
\hline Diffusion: 20-Year-old-Birth Rate & 9.07 & $\begin{array}{c}0.132 \\
{[0.069]}\end{array}$ & $\begin{array}{c}0.057 \\
{[0.057]}\end{array}$ \\
\hline Diffusion: 21-Year-old-Birth Rate & 10.00 & $\begin{array}{c}0.103 \\
{[0.084]}\end{array}$ & $\begin{array}{c}0.032 \\
{[0.081]}\end{array}$ \\
\hline
\end{tabular}

Column 1 shows the mean birth rate (in levels) for the relevant age group across the 7,498 countyby-year observations in the sample. Each coefficient in columns 2 and 3 comes from a separate regression. In each regression, the dependent variable is the logged birth rate for women of a particular age. All regressions include the right-hand side controls from earlier tables, along with county fixed effects and year fixed effects. Standard errors clustered by county are in brackets. 
Table 5: Counseling and Non-Counseling Diffusion

\begin{tabular}{lcccccc}
\hline & \multicolumn{2}{c}{ Baseline } & \multicolumn{2}{c}{ With 20-24 Birth Rate } & \multicolumn{3}{c}{$\begin{array}{c}\text { With 20-24 Birth Rate } \\
\text { \& RH Interactions }\end{array}$} \\
\hline \multirow{3}{*}{ Diffusion without Counseling } & $(1)$ & $(2)$ & $(3)$ & $(4)$ & $(5)$ & $(6)$ \\
& 0.181 & 0.141 & 0.128 & 0.129 & 0.119 & 0.191 \\
Diffusion with Counseling & {$[0.034]$} & {$[0.034]$} & {$[0.043]$} & {$[0.028]$} & {$[0.059]$} & {$[0.052]$} \\
& -0.193 & -0.145 & -0.064 & -0.074 & -0.048 & -0.034 \\
County Trends & {$[0.103]$} & {$[0.085]$} & {$[0.077]$} & {$[0.076]$} & {$[0.094]$} & {$[0.094]$} \\
Test of Equality F(1,395) & Linear & Quadratic & Linear & Quadratic & Linear & Quadratic \\
Observations & 12.87 & 10.57 & 5.00 & 6.63 & 2.61 & 5.87 \\
R-squared & 7,498 & 7,498 & 7,498 & 7,498 & 7,498 & 7,498 \\
The & 0.982 & 0.988 & 0.986 & 0.989 & 0.986 & 0.990 \\
\hline
\end{tabular}

The dependent variable is the log of the birth rate among women ages 15 to19; in each column both coefficients are from the same regression. All regressions include the right-hand side controls described under Table 2, and year and county fixed effects. Regressions are weighted by the population of women ages 15 to 19 as of 1990 . There are 12 counties with districts

implementing counseling programs and there are 9 counties with programs that do not mandate counseling (see text). The Fstatistic is from a Wald test of equality of the diffusion effect for the counties with counseling and the counties without counseling; the 1-percent critical value of the $F(1,395)$ distribution is 6.70 and the 10 -percent critical value is 2.72 . In columns 3 and 4, the logged birth rate for ages 20-24 is included as a control. In the last two columns, a dummy for being a treatment county is interacted with the right-hand side controls listed in the text under equation (1) and below Table 3. 
Table 6: Counseling and Non-Counseling with Other Interacted Covariates

\begin{tabular}{|c|c|c|c|c|c|c|}
\hline & Baseline & $\begin{array}{l}\text { Per-Capita } \\
\text { Income }\end{array}$ & Population & $\begin{array}{l}\text { Percent } \\
\text { Hispanic }\end{array}$ & $\begin{array}{l}\text { Percent } \\
\text { White }\end{array}$ & $\begin{array}{c}\text { Percent } \\
\text { Black }\end{array}$ \\
\hline Diffusion without Counseling & $\begin{array}{c}(1) \\
0.181 \\
{[0.034]}\end{array}$ & $\begin{array}{c}(2) \\
0.19 \\
{[0.037]}\end{array}$ & $\begin{array}{c}(3) \\
0.163 \\
{[0.029]}\end{array}$ & $\begin{array}{c}(4) \\
0.150 \\
{[0.045]}\end{array}$ & $\begin{array}{c}(6) \\
0.177 \\
{[0.034]}\end{array}$ & $\begin{array}{c}(5) \\
0.204 \\
{[0.044]}\end{array}$ \\
\hline Diffusion with Counseling & $\begin{array}{l}-0.193 \\
{[0.103]}\end{array}$ & $\begin{array}{l}-0.159 \\
{[0.118]}\end{array}$ & $\begin{array}{l}-0.195 \\
{[0.103]}\end{array}$ & $\begin{array}{l}-0.204 \\
{[0.107]}\end{array}$ & $\begin{array}{l}-0.208 \\
{[0.095]}\end{array}$ & $\begin{array}{l}-0.178 \\
{[0.097]}\end{array}$ \\
\hline $\begin{array}{c}\text { Diffusion } \times \text { Above-Average } \\
\text { Covariate Value }\end{array}$ & - & $\begin{array}{l}-0.041 \\
{[0.044]}\end{array}$ & $\begin{array}{c}0.01 \\
{[0.025]}\end{array}$ & $\begin{array}{c}0.023 \\
{[0.033]}\end{array}$ & $\begin{array}{c}0.069 \\
{[0.092]}\end{array}$ & $\begin{array}{l}-0.023 \\
{[0.030]}\end{array}$ \\
\hline Test of Equality $F(1,395)$ & 12.95 & 9.16 & 12.39 & 15.55 & 15.72 & 14.88 \\
\hline $\begin{array}{l}\text { Observations } \\
\text { R-squared }\end{array}$ & $\begin{array}{l}7,498 \\
0.982\end{array}$ & $\begin{array}{l}7,498 \\
0.982\end{array}$ & $\begin{array}{l}7,498 \\
0.982\end{array}$ & $\begin{array}{l}7,498 \\
0.982\end{array}$ & $\begin{array}{l}7,498 \\
0.982\end{array}$ & $\begin{array}{l}7,498 \\
0.982\end{array}$ \\
\hline
\end{tabular}

The dependent variable is the log of the birth rate among women ages 15 to19; in each column all coefficients are from the same regression. All regressions include the right-hand side controls described under Table 2, year dummies, county fixed effects, and linear trends. Regressions are weighted by the population of women ages 15 to 19 as of 1990. The F-statistic is from a Wald test of equality of the diffusion effect for the counties with counseling and the counties without counseling; the 1-percent critical value of the $F(1,395)$ distribution is 6.70 and the 10 -percent critical value is 2.72 . The first column repeats the estimates from column (1) in Table 5. The next column adds a variable that interacts a dummy for condom diffusion with a dummy for whether a county has above-average per-capita income (where the average is calculated among diffusion counties only); each subsequent column adds in a similar interacted term using a different covariate. Redoing column 2 with quadratic trends yields non-counseling and counseling coefficients of 0.15 [0.04] and -0.12 [0.10]; for column 3, 0.15 [0.04] and -0.14 [0.09]; for column 4, 0.15 [0.06] and -0.14 [0.10]; for column 5, 0.13 [0.04] and -0.17 [0.07]; and for column 6, 0.25 [0.05] and -0.08 [0.07]. 
Table 7: Condom Diffusion Programs and Gonorrhea Rates for Women

\begin{tabular}{lccccc}
\hline & \multicolumn{2}{c}{ Log Birth Rate } & & \multicolumn{2}{c}{$\begin{array}{c}\text { Log Gonorrhea } \\
\text { Rate (Women) }\end{array}$} \\
\cline { 2 - 3 } \cline { 5 - 6 } & $(1)$ & $(2)$ & & $(3)$ & $(4)$ \\
\hline Diffusion & 0.123 & & & 0.747 & \\
& {$[0.038]$} & & & {$[0.386]$} & \\
Diffusion without & & 0.141 & & \multicolumn{2}{c}{0.923} \\
Counseling & & {$[0.034]$} & & & {$[0.384]$} \\
Diffusion with & & 0.074 & & & 0.264 \\
Counseling & & {$[0.063]$} & & \multicolumn{2}{c}{$[0.495]$} \\
RHS Controls & Yes & Yes & & Yes & Yes \\
Year Dummies & Yes & Yes & & Yes & Yes \\
City FEs & Yes & Yes & & Yes & Yes \\
Observations & 629 & 629 & & 629 & 629 \\
\hline
\end{tabular}

For columns (1)-(3), the dependent variable is the log of the birth rate among women ages 15 to19. For coumns (4)-(6), the dependent variable is the log of the gonorrhea rate for women. Standard errors are clustered by county. The sample is limited to 59 cities with populations over 200,000, with available data from the CDC on the gonorrhea rates for women between 1989 and 1999. Cities are assigned the treatment status of the county in which they are primarily located. Right-hand side controls include a linear city-specific time trend, the number of years that crack cocaine has been in the city and its square, per-capita income, per capita Medicaid transfers, state unemployment insurance compensation per capita, total population in levels and logs, the fraction of the population Hispanic, fraction white, fraction under 18 , the fraction poor and under 18 , and the fraction over age 65 . Regressions are weighted by the population of women ages 15 to 19 as of 1990 . 
Figure 1:

Ratio of Teen Fertility to Fertility of Women 20-24,

in Years Before and After School Distribution Program

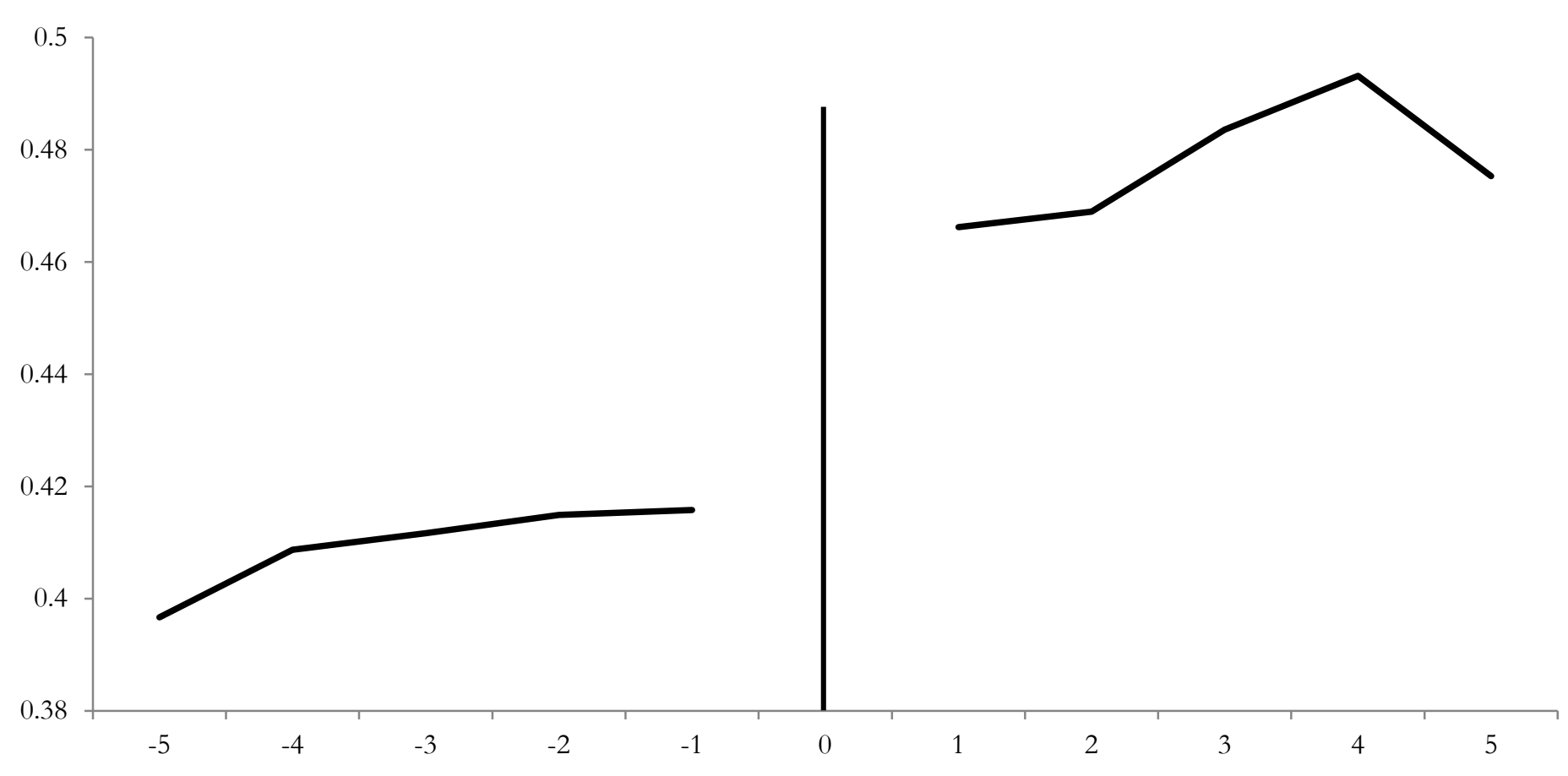

The figure shows relative teen fertiliy for the counties implementing a school condom program. The ratio is defined as the total number of births conceived by women ages 15 to 19 in the county and year, divided by the total number of births conceived by women ages 20 to 24 . This ratio is averaged across the counties annually starting 5 years before diffusion through 5 years after diffusion (year zero is the year a program was implemented). 
Figure 2:

Results for Treatment Counties by Counseling Status

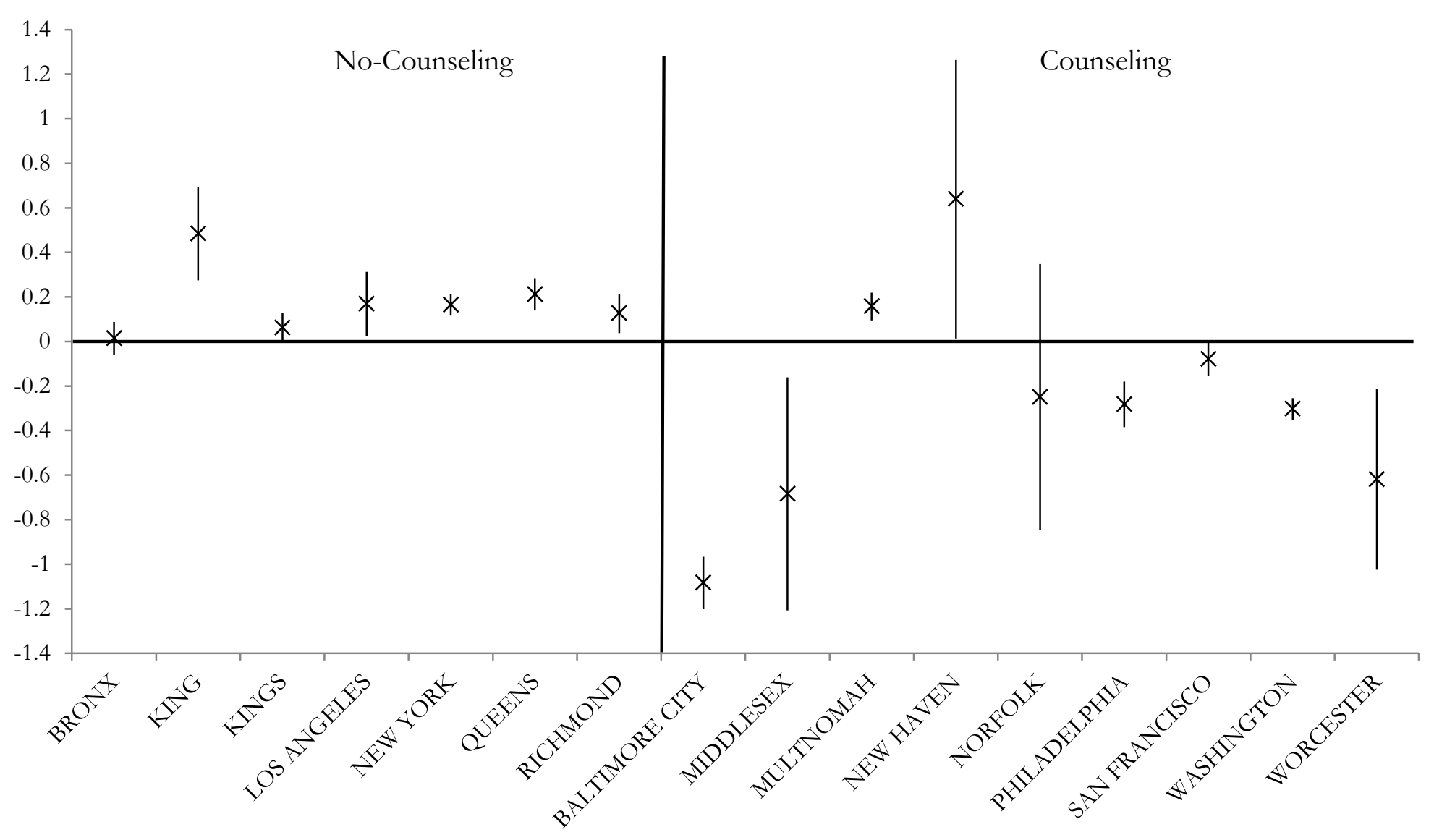

Each point in the above picture is a coefficient from a separate regression. Each regression redoes the estimate in column 2 of Table 2 except that all the treatment counties except for one are dropped from the sample; the diffusion coefficient is then reported. The above picture shows the results from regressions keeping a treatment county with at least 10,000 females ages 15 to 19 in 1990 ; several of the smaller counties are omitted (see text). The dashed lines represent 95\% confidence intervals for each coefficient. 
Appendix Table 1: Districts with Condom Diffusion Programs

\begin{tabular}{|c|c|c|c|}
\hline District & Year & $\begin{array}{l}\text { Opt-In/ } \\
\text { Opt-Out? }\end{array}$ & $\begin{array}{c}\text { Basket/ } \\
\text { Vending Machine }\end{array}$ \\
\hline Adams County School District 14 & 1989 & Yes & - \\
\hline Baltimore City Public School System & 1990 & No & - \\
\hline Cambridge Public School District & 1990 & $?$ & - \\
\hline New York City Public Schools & 1991 & $1994+$ & - \\
\hline Brookline Public School District & 1992 & $?$ & - \\
\hline Culver City Unified School District & 1992 & No & - \\
\hline District of Columbia Public Schools & 1992 & No & - \\
\hline Falmouth School District & 1992 & No & Yes \\
\hline LA-Unified School District & 1992 & Yes & - \\
\hline Lincoln-Sudbury School District & 1992 & $?$ & Yes \\
\hline Newton Public Schools & 1992 & $?$ & - \\
\hline Portland Public Schools & 1992 & ? & - \\
\hline Portsmouth School District & 1992 & Yes & - \\
\hline $\begin{array}{l}\text { Public Schools of Northborough and } \\
\text { Southborough }\end{array}$ & 1992 & $?$ & - \\
\hline San Fransisco Unified School District & $1992^{*}$ & Yes & - \\
\hline Santa Monica-Malibu Unified School District & 1992 & No & - \\
\hline School District of Philadelphia & $1992^{\ddagger}$ & Yes & - \\
\hline Alexandria City Public Schools & 1993 & $?$ & - \\
\hline $\begin{array}{l}\text { Amherst-Pelham Regional Public School } \\
\text { District }\end{array}$ & 1993 & $?$ & - \\
\hline New Haven Public Schools & 1993 & $?$ & - \\
\hline Seattle Public School District & $1993^{\dagger}$ & No & Yes \\
\hline Wachusett Regional School District & 1993 & No & Yes \\
\hline
\end{tabular}

${ }^{\ddagger}$ Philadelphia had a pilot program with several schools in December of 1991.

*1991 for Balboa High, 1992 for others

${ }^{\dagger}$ Condoms were diffused over time to schools in Seattle from 1993 to 1995

The last column denotes districts where we have documentation that diffusion was provided via condoms or vending machines. 
Appendix Table 2: Dropping Each County

\begin{tabular}{lcclcc}
\hline County Excluded: & Trends & $\begin{array}{c}\text { Q. } \\
\text { Trends }\end{array}$ & County Excluded: & Trends & $\begin{array}{c}\text { Q. } \\
\text { Trends }\end{array}$ \\
\hline All Counties & 0.128 & 0.097 & Worcester & 0.127 & 0.095 \\
(baseline) & {$[0.045]$} & {$[0.041]$} & & {$[0.047]$} & {$[0.043]$} \\
Los Angeles & 0.133 & 0.084 & Rockingham & 0.126 & 0.095 \\
San Francisco & {$[0.059]$} & {$[0.048]$} & & {$[0.047]$} & {$[0.043]$} \\
& 0.137 & 0.106 & Bronx & 0.133 & 0.102 \\
Adams & {$[0.046]$} & {$[0.042]$} & & {$[0.050]$} & {$[0.046]$} \\
New Haven & 0.127 & 0.096 & Kings & 0.123 & 0.101 \\
Washington & {$[0.047]$} & {$[0.043]$} & & {$[0.056]$} & {$[0.049]$} \\
Baltimore City & 0.126 & 0.094 & New York & 0.103 & 0.076 \\
Barnstable & {$[0.047]$} & {$[0.043]$} & & {$[0.054]$} & {$[0.051]$} \\
& 0.151 & 0.115 & Queens & 0.100 & 0.071 \\
Hampshire & {$[0.037]$} & {$[0.037]$} & & {$[0.050]$} & {$[0.046]$} \\
& 0.130 & 0.098 & Richmond & 0.128 & 0.095 \\
Middlesex & {$[0.046]$} & {$[0.043]$} & & {$[0.048]$} & {$[0.044]$} \\
Norfolk & 0.128 & 0.096 & Multnomah & 0.127 & 0.094 \\
& {$[0.047]$} & {$[0.043]$} & & {$[0.048]$} & {$[0.044]$} \\
\hline & 0.126 & 0.094 & Philadelphia & 0.131 & 0.102 \\
& {$[0.047]$} & {$[0.043]$} & & {$[0.046]$} & {$[0.042]$} \\
& 0.128 & 0.096 & Alexandria & 0.129 & 0.098 \\
& {$[0.046]$} & {$[0.043]$} & & {$[0.047]$} & {$[0.043]$} \\
& 0.127 & 0.096 & King & 0.129 & 0.095 \\
& {$[0.047]$} & {$[0.043]$} & & {$[0.047]$} & {$[0.043]$} \\
\hline
\end{tabular}

Each Coefficient is from a separate regression and shows the diffusion coefficient estimates from the specification in columns 1 and 2, Table 2, which a particular treatment county omitted from the sample. The original baseline estimate is given in the first row on the left. 


\section{Appendix Figure 1: Distributin of Betas from Permutation Test}

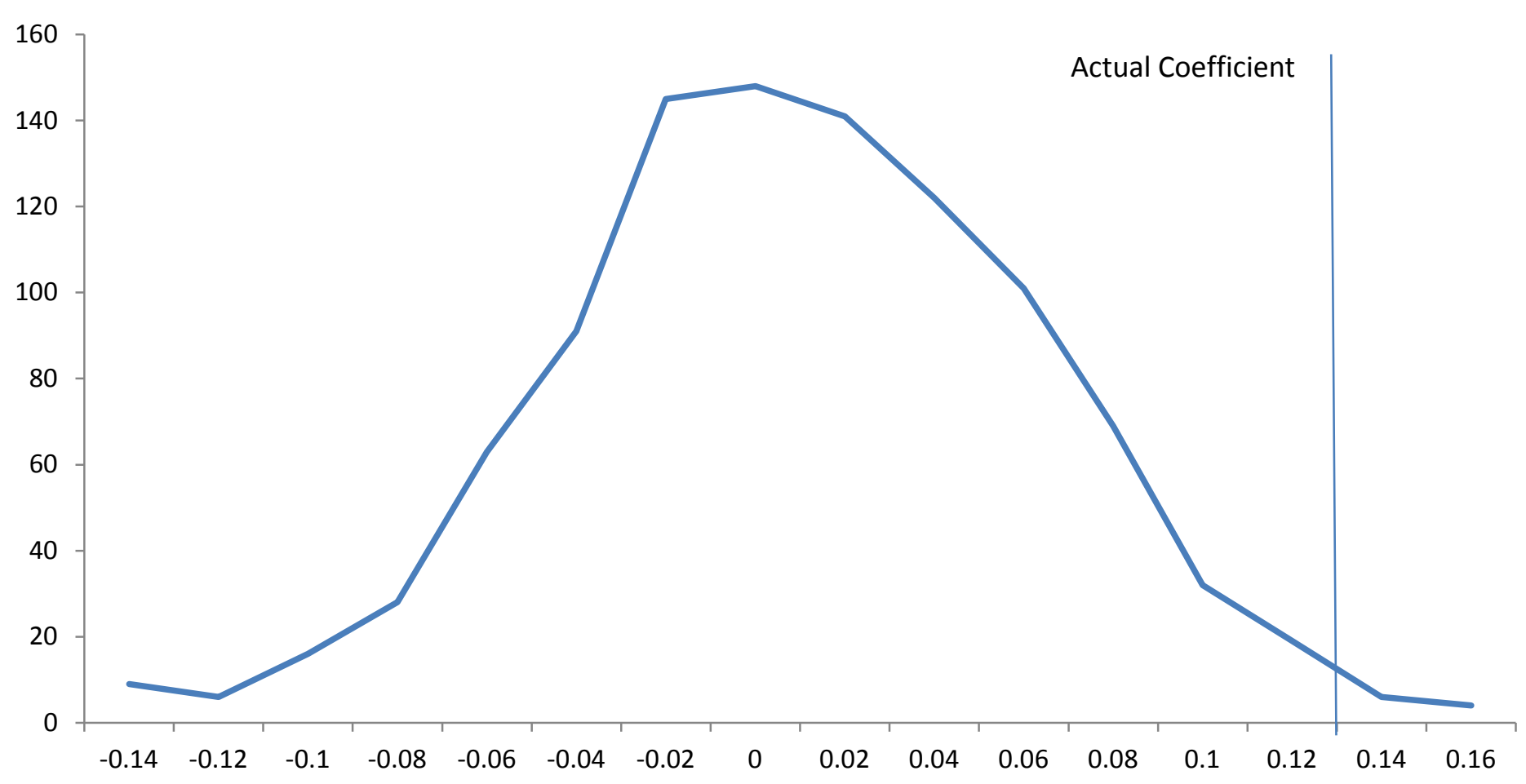

The picture shows the frequency distribution of 1,000 "placebo" regressions. In each regression, the diffusion profile from 1982 to 2000 for each treatment county was randomly assigned, without replacement, to another county in the sample, the baseline regression was then repeated where the real diffusion variable was replaced by this randomly generated variable. The coefficient from the actual diffusion is in 99th percentile of the above distribution. 